\title{
The role of the GH-IGF-I axis in the regulation of myocardial growth: from experimental models to human evidence
}

\author{
Serafino Fazio, Emiliano Antonio Palmieri, Bernadette Biondi ${ }^{1}$, Antonio Cittadini and Luigi Saccà \\ Department of Clinical Medicine, Cardiovascular and Immunological Science, University Federico II Medical School, 80131 Naples, Italy and \\ ${ }^{1}$ Department of Molecular and Clinical Endocrinology and Oncology, University Federico II Medical School, 80131 Naples, Italy \\ (Correspondence should be addressed to S Fazio, Medicina Interna, Via S. Pansini 5, 80131 Napoli, Italy; Fax: +39 081 7463199 )
}

\section{Introduction}

\section{From systemic to myocardial GH-IGF-I axis}

Growth hormone $(\mathrm{GH})$ is a peptide hormone synthesized and secreted by the anterior pituitary gland. In normal conditions, its synthesis and secretion are strictly regulated by the integrated and coordinated actions of two hypothalamic neurohormones: GH releasing factor and $\mathrm{GH}$ inhibiting factor (i.e., somatostatin). The ratio between the hypothalamic secretion of these two factors represents the basic and dynamic mechanism by which neurologic as well as extraneurologic influences may functionally affect $\mathrm{GH}$ secretion under physiologic or pathophysiologic conditions (1).

Biological effects of $\mathrm{GH}$ are mediated by the interaction with a specific transmembrane receptor (GHR), expressed in almost all cellular types. As a consequence of GH-GHR interaction on target tissues, GH may exert direct metabolic effects. However, the most relevant biological effects of $\mathrm{GH}$ are indirect and to a large extent mediated by the stimulation of expression of insulinlike growth factor-I (IGF-I), in the liver (endocrine action) and in peripheral tissues (autocrine/paracrine action). Only a small amount of liver-derived IGF-I circulates as a free hormone, which is responsible for the biological actions. Indeed, the bulk of circulating IGF-I is bound to its specific carrier proteins, called IGF-binding proteins (IGF-BPs), the most important of which seems to be IGF-BP-3, since it binds more than $95 \%$ of IGF-I in the blood $(1,2)$. Furthermore, the IGF-I/ IGF-BP-3 dimer forms a complex with another protein subunit, the acid-labile subunit, and in this ternary complex the IGF-I has a serum half-life of many hours. Both the acid-labile subunit and IGF-BP-3 are principally synthesized in the liver, and their serum concentrations are influenced by circulating GH levels. IGF-BPs serve not only to transport IGF-I in the circulation, but also to prolong its half-life, to modulate its tissue specificity, and to potentiate or neutralize its biological actions. Moreover, a number of studies have shown that IGF-BPs modify the biological effects of IGF-I on a variety of mammalian cells.

The relative importance of circulating versus locally produced IGF-I in the anabolic and growth-promoting effects of GH has recently been addressed by Sjögren et al. and Yakar et al. $(3,4)$. By using a novel tissuespecific recombinant system, the two groups independently concluded that, although hepatic IGF-I is the major contributor to circulating IGF-I levels, it is not crucial for normal postnatal growth, providing direct evidence for the importance of an autocrine/paracrine role for IGF-I.

In this scenario, a large body of evidence has accumulated to support the concept that the GH-IGF-I axis targets the heart (5-9). In particular, it has been demonstrated that GHRs are largely expressed in the myocardium (9) and that, by interacting with GH, they stimulate the local biosynthesis of IGF-I, which may act in an autocrine or paracrine manner by binding specifically to its high-affinity membrane-associated receptor (Fig. 1). In this regard, it has been shown that myocardial IGF-I expression and content strictly parallel circulating GH levels (5-8). Studies in both animals and humans have provided consistent evidence that the GH-IGF-I axis is involved in the regulation of myocardial structure and function. In particular, a large number of studies have consistently shown that $\mathrm{GH}$ and IGF-I are critically involved in the regulation of cardiomyocyte growth.

\section{GH-IGF-I axis and the regulation of myocardial growth}

\section{In vitro studies}

In response to an appropriate biomechanical hypertrophic stimulus, cardiac myocytes show increased protein content with increase in cellular mass and volume. In particular, in addition to an overall increase in protein and RNA content, the hypertrophic process is mainly characterized by the increase in myofibrillogenesis with accumulation of sarcomeres, and alterations in gene expression (both upregulation and downregulation), involving immediate-early proto-oncogenes and embryonic genes. The 'fetal' pattern of gene expression, by causing an isoform rearrangement of several contractile proteins, represents one of the most peculiar features of the 


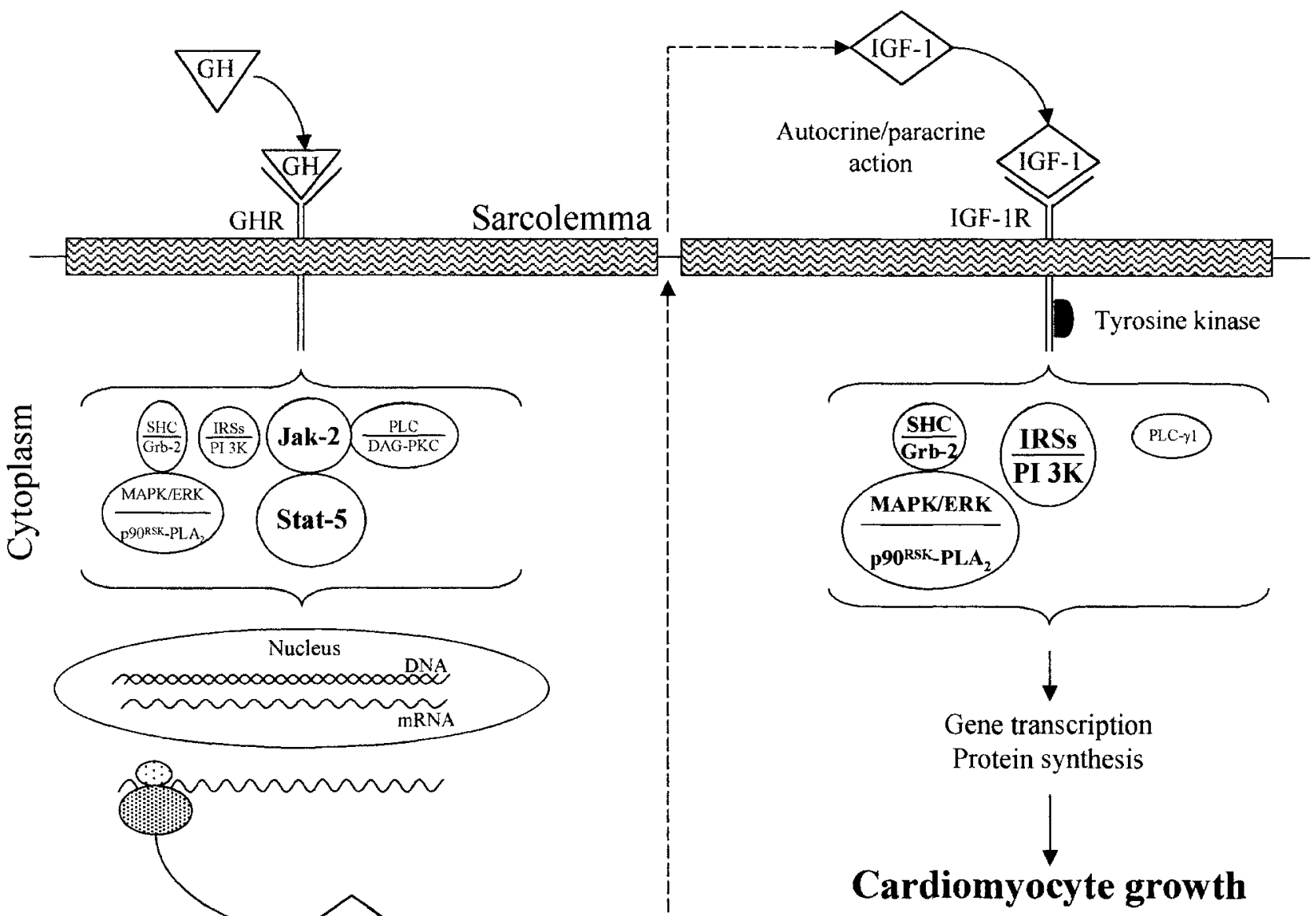

Figure 1 Simplified scheme of autocrine/paracrine IGF-I-mediated GH action in the regulation of cardiomyocyte growth and possible signaling pathways initiated by binding of GH and IGF-I to their receptors. Jak: Janus kinase; stat: signaling transducers and activators of transcription; MAPK/ERK: mitogen-activated protein kinase/extracellular signal-regulated kinase; SHC: src homology/collagen; Grb: growth factor receptor-binding protein; IRSs: insulin receptor substrates; PI 3K: phosphatidylinositol 3-kinase; PLC: phospholipase C; DAG: 1,2-diacylglycerol; PKC; protein kinase C; p90 RSK: p90 S6 kinase; PLA 2 : phospholipase $A_{2}$; PLC- $\gamma 1$ : phospholipase C- $\gamma 1$.

hypertrophic process and makes it different from the normal maturational growth. In this scenario, the first demonstration that IGF-I directly induces cardiac hypertrophy came from Ito and coworkers (10), who demonstrated that IGF-I, but not GH, acts directly in cultured neonatal cardiomyocytes to induce a significant dose-dependent increase of transcripts of musclespecific genes, such as myosin light chain-2, skeletal muscle $\alpha$-actin, and troponin I. This is followed by induction of protein synthesis and a two-fold increase in myocyte cell size. Moreover, it was also reported that the addition of IGF-BP-3 to cultured cardiomyocytes completely inhibits these biological responses, suggesting an inhibitory effect of IGFBP-3 on IGF-Iinduced cardiac hypertrophy.

The intracellular signal pathway(s) involved in the transduction of IGF-I-induced cardiomyocyte hypertrophy was systematically investigated by Foncea and coworkers (11). The authors concluded that, in primary rat cultured cardiomyocytes, IGF-I activates multiple signal transduction pathways that involve IGF-IR $\beta$-1 subunit autophosphorylation, tyrosine phosphorylation of insulin receptor substrate (IRS)-1, phosphatidylinositol (PI) 3-kinase, phospholipase C (PLC)- $\gamma 1$, activation of the mitogen-activated protein kinase (MAPK)-extracellular signal-regulated kinase (ERK) cascade, and p90 S6 kinase (RSK), which were associated with an increased protein synthesis, as assessed by $\left[{ }^{3} \mathrm{H}\right]$ phenylalanine incorporation into cardiomyocyte proteins.

Taken together, these data clearly indicate that IGF-I, by binding to its specific high affinity sarcolemmatic receptor, activates a multiple signal transduction pathway which, in turn, induces muscle-specific genes and increases protein synthesis with accumulation of myofibrils and increase in myocyte cell mass and volume (Fig. 1) (12). 


\section{In vivo studies}

The in vivo stimulatory effect of IGF-I on protein synthesis was recently addressed by Bark and coworkers in the mouse (13). By measuring daily protein turnover in several tissues, they showed that acute intravenous infusion of IGF-I induced a significant increase in protein synthesis, mainly localized to muscle tissue, and particularly to the heart, which was unaccompanied by significant changes in blood glucose.

The involvement of the GH-IGF-I axis in the regulation of myocardial growth in vivo has been largely investigated in the last years in several animal models. Cittadini and coworkers (14), by administering GH, or IGF-I, or GH + IGF-I for 4 weeks to normal adult rats, found that rats receiving either GH, or IGF-I, or the combination showed significant increase of the left ventricular $(\mathrm{LV})$ weight compared with placebo-treated rats. In particular, rats receiving GH+IGF-I did not show additional hypertrophy compared with rats treated with GH or IGF-I alone, suggesting that the in vivo $\mathrm{GH}$-induced cardiac hypertrophic response was mediated by circulating and/or locally synthesized IGF-I.

Similarly, Duerr and coworkers (15) found that IGF-I administered subcutaneously resulted in a significant LV hypertrophy in normal rats compared with controls. Moreover, they reported that IGF-I administered early during the onset of experimental post-infarction cardiac failure enhanced the hypertrophic response of viable myocardium compared with control rats.

More recently, these findings were confirmed by Grimm and coworkers (16) in normal rats receiving subcutaneous injections of GH for 28 days. They found that GH induced LV hypertrophy, as documented by the significant increase of left ventricle to body weight ratio, diastolic posterior wall thickness, and cardiomyocyte width. Again, by administering GH early following experimental myocardial infarction, they found that GH induced a significant hypertrophy of the viable myocardium, regardless of infarct size.

It is important to emphasize that cardiac hypertrophy produced by GH-IGF-I axis activation in the abovementioned animal models consistently translated into significant enhancement of systolic and diastolic $\mathrm{LV}$ function and was not accompanied by increase in collagen content (14-16). These effects were evident in experimental post-infarction models in which GH-IGF-I, given early after myocardial infarction, improved LV function, enhanced cardiomyocyte hypertrophy, and reduced adaptive fibrosis in non-infarcted myocardium $(15,16)$.

Taken together, these findings strongly suggest that GH-IGF-I-induced myocardial hypertrophy, at least in the short-term, may be considered physiologic, since enhanced myocardial fibrosis is well known to accompany hypertrophy due to cardiac overload.

IGF-I might be one of the mediators of the hypertrophic response due to hemodynamic challenge. In models of pressure overload secondary to aortic banding or renal hypertension $(17,18)$, it was shown that IGF-I mRNA expression increased in the myocardium, at an early stage of LV hypertrophy and to a greater extent in the myocardial segments exposed to the highest stress $(18,19)$. Moreover, GHR and IGF-I levels were shown to increase in the right ventricle after induction of volume overload from aorto-caval fistula (19).

These findings place the relation of the GH-IGF-I axis to cardiac hypertrophy in a new and more complex mechanistic perspective, suggesting that $\mathrm{GH}$ and IGF-I play an important role in the sequence of events that control cardiac growth.

\section{Human studies}

The importance of the GH-IGF-I axis in the regulation of cardiac growth in humans has been extensively addressed in the last few years and has been inferred from cross-sectional assessment of cardiac phenotype in clinical states of altered GH secretion, such as adultand childhood-onset GH deficiency and acromegaly, in clinical states of peripheral GH resistance, such as anorexia, and in preliminary studies of $\mathrm{GH}$ treatment of heart failure.

Cardiac involvement in GH deficiency was shown to be strictly dependent on the age at which GH deficiency sets in. GH deficiency acquired in adult life is associated with a decreased LV mass. However, this finding is not impressive and not found in all patients (20-24). Conversely, childhood-onset GH deficiency is unequivocally associated with reduced cardiac mass, mainly due to reduction of wall thickness (25-27). A direct causative role for the GH-IGF-I axis in these cardiac abnormalities is strongly supported by the significant increase of LV mass following replacement therapy, which is particularly impressive in those patients with the childhood-onset form of the disease $(27,28)$, thus suggesting that the integrity of GH-IGF-I axis is essential for cardiac development and that it plays a relevant role in preserving cardiac morphology in adult life.

The pure consequences of GH and IGF-I overactivity on cardiac mass in humans have not been easy to isolate, since acromegaly is often associated with such major complications as systemic hypertension, diabetes mellitus, and coronary artery disease, which may per se affect myocardial growth. Nevertheless, studies performed in groups of patients affected by the uncomplicated form of active acromegaly clearly showed significant LV hypertrophy, mainly due to increased wall thickness $(29,30)$. Also in this case, a causative role for $\mathrm{GH}$ in these cardiac abnormalities is strongly suggested by the significant reduction of LV mass following treatment with the somatostatin analog, octreotide, which paralleled the reduction of circulating GH and IGF-I levels (31-33). 
The key role of the GH-IGF-I axis in the regulation of myocardial growth was also addressed in a recent randomized, double-blind, placebo-controlled study performed in adolescent women affected by anorexia nervosa treated with GH. The results of this study clearly showed that a 4 week treatment with $\mathrm{GH}$ induced a significant increase in LV mass compared with placebo (34).

Further evidence comes from three single case reports describing severe dilated cardiomyopathy associated with acquired GH deficiency in the adult life which were unresponsive to conventional therapy but successfully treated with replacement GH therapy (35-37). In all the three reports, the impressive improvement of the clinical status following $\mathrm{GH}$ administration was accompanied by increased LV relative wall thickness (RWT=LV wall thickness/LV radius) due to the contemporary increase of wall thickness and the reduction of the cavity dimension. In one of these studies, the effect of GH was histologically documented, and it was clearly shown that GH therapy significantly increased myocyte fibrillar content and cardiomyocyte width compared with pretreatment features (36).

The stimulatory effect of $\mathrm{GH}$ on myocardial growth has also been found in three recent clinical studies addressing $\mathrm{GH}$ effect in the treatment of idiopathic and/or post-ischemic dilated cardiomyopathy, in which short-term GH administration resulted in a significant increase of $\mathrm{LV}$ mass with a unique pattern of $\mathrm{LV}$ concentric remodeling, due to increased ventricular wall thickness and reduced or unchanged cavity dimension (Fig. 2) (38-40).

\section{GH-IGF-I axis and cardiomyocyte loss}

Besides promoting cardiomyocyte growth, the $\mathrm{GH}-$ IGF-I axis may also influence the trophic status of the myocardium by preventing cardiomyocyte loss, and particularly by attenuating cardiomyocyte apoptosis $(41,42)$ (Fig. 2).

In this regard, a systematic investigation of the biochemical basis of cardiomyocyte apoptosis and the anti-apoptotic properties of IGF-I has recently been performed by Wang and coworkers in cultured rat cardiomyocyte (43). The data indicate that the biochemical apoptotic machine is constitutively expressed within cardiomyocytes and that, under basal conditions, it is turned off by tonic survival signals, most of which move in from the serum. In fact, serum deprivation rapidly triggers cardiomyocyte apoptosis, which is significantly enhanced by the co-exposure of cardiomyocytes to doxorubicin, a well-known potent cardiotoxic agent. The systematic assessment of the signal pathway(s) mostly involved in apoptosis showed that both conditions were associated with rapid activation of the Bax-Caspase-3 cascade. Interestingly, IGF-I significantly attenuated both serum-free and doxorubicin-induced cardiomyocyte apoptosis and in both cases

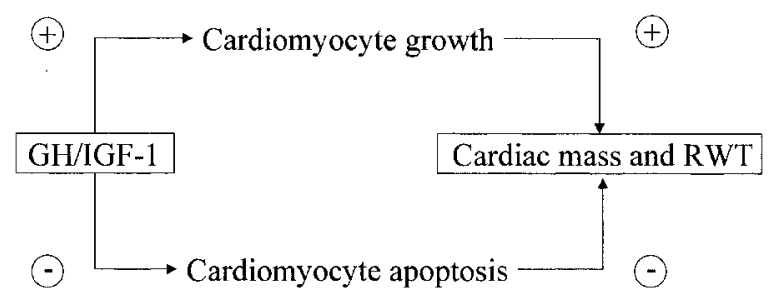

Figure 2 Simplified diagram of GH-IGF-I actions in the regulation of cardiac mass and relative wall thickness (RWT).

this effect was associated with attenuation of BaxCaspase-3 activation.

On the basis of these observations, the detection of apoptosis in myocytes in acromegaly, recently reported by Frustaci and coworkers (44), may appear unexpected. However, it must be recognized that overt and long-term acromegaly is often complicated by systemic hypertension, diabetes mellitus and coronary artery disease, which may play a significant and predominant role in triggering cardiomyocyte apoptosis in this clinical setting. On the other hand, it might be also speculated that, as for other hormonal substances, chronic high levels of circulating IGF-I may have resulted in a downregulation or in a desensitization of IGF-IR.

\section{Conclusion}

The data presented in this brief review indicate that the GH-IGF-I axis is a novel endogenous regulator of myocardial growth and suggest that its primary or secondary alteration may significantly impact on myocardial structural homeostasis, with relevant pathophysiological consequences.

The evidence available also indicates that shortterm exogenous modulation of the GH-IGF-I axis might be largely beneficial in the management of several cardiovascular disease states in which regulation of myocardial mass is crucial.

\section{References}

1 Thorner MO, Vance ML, Horvath E \& Kovacs K. The anterior pituitary. In Williams Textbook of Endocrinology, edn 8, pp 221310. Eds JD Wilson \& DW Foster. Philadelphia: WB Saunders Co, 1992.

2 Jones JI \& Clemmons DR. Insulin-like growth factors and their binding proteins: biological actions. Endocrine Reviews 199516 $3-34$.

3 Sjögren K, Liu JL, Blad K, Skrtik S, Vidal O, Wallenius V et al. Liver-derived insulin-like growth factor I (IGF-I) is the principal source of IGF-I in blood but is not required for postnatal body growth in mice. Proceedings of the National Academy of Sciences of the USA $1999967088-7092$.

4 Yakar S, Liu JL, Stannard B, Butler A, Accili D, Sauer B et al. Normal growth and development in absence of hepatic insulin-like growth factor I. Proceedings of the National Academy of Sciences of the USA $1984967324-7329$.

5 D'Ercole AJ, Stiles AD \& Underwood LE. Tissue concentrations 
of somatomedin C: further evidence for multiple sites of synthesis and paracrine or autocrine mechanisms of action. Proceedings of the National Academy of Sciences of the USA 1984 81 935-939.

6 Thorner MO \& Vance ML. Growth hormone. Journal of Clinical Investigation 198882 745-747.

7 Saccà L, Cittadini A \& Fazio S. Growth hormone and the heart. Endocrine Review 199415 555-573.

8 Isgaard J \& Friberg P. Regulation of insulin-like growth factor I (IGF-I) and receptors for IGF-I and growth hormone in the heart. Endocrinology and Metabolism 19974 15-19.

9 Mathews LS, Enberg B \& Norstedt G. Regulation of rat growth hormone receptor gene expression. Journal of Biological Chemistry 198917 9905-9910.

10 Ito H, Hiroe M, Hirata Y, Motoyoshy T, Adachi S, Masayoshi S et al. Insulin-like growth factor-I induces hypertrophy with enhanced expression of muscle specific genes in cultured rat cardiomyocytes. Circulation 199387 1715-1721.

11 Foncea R, Andersson M, Ketterman A, Blakesley V, SapagHagar M, Sugden PH et al. Insulin-like growth factor-I rapidly activates multiple signal transduction pathways in cultured rat cardiac myocytes. Journal of Biological Chemistry 1997272 19115-19124.

12 Fantl WJ, Johnson DE \& Williams LT. Signaling by receptor tyrosine kinases. Annual Review of Biochemistry 199362 453-457.

13 Bark TH, McNurlan MA, Lang $\mathrm{CH}$ \& Garlick PJ. Increased protein synthesis after acute IGF-I or insulin infusion is localized to muscle in mice. American Journal of Physiology 1998275 E118-E123.

14 Cittadini A, Strömer H, Katz SE, Clark R, Moses AC, Morgan JP et al. Differential cardiac effects of growth hormone and IGF-I in the rat: a combined in vivo and in vitro evaluation. Circulation $199693800-809$.

15 Duerr RL, Huang S, Miraliakbar HR, Clark R, Chien KR \& Ross J Jr. Insulin-like growth factor I enhances ventricular hypertrophy and function during the onset of experimental cardiac failure. Journal of Clinical Investigation 199595619 627.

16 Grimm D, Cameron D, Griese DP, Riegger GAJ \& Kromer E. Differential effects of growth hormone on cardiomyocyte and extracellular matrix protein remodeling following experimental myocardial infarction. Cardiovascular Research 199840 297-306.

17 Hanson MC, Kenneth AF, Alexander RW \& De Lafontaine P. Induction of cardiac insulin-like growth factor I gene expression in pressure overload hypertrophy. American Journal of Medical Science 1993306 69-74.

18 Wahlander H, Isgaard J, Jennische E \& Friberg P. Left ventricular insulin-like growth factor I increases in early renal hypertension. Hypertension $19921925-32$.

19 Friberg P, Adams MA, Isgaard J, Wickmann A \& Wahlander H. Right but not left ventricular insulin-like growth factor I (IGF-I) and growth hormone (GH)-receptor levels increase after induction of volume overload. Hypertension 199322 418(A65).

20 Cuneo RC, Salomon F, Wilmshurst P, Byrne C, Wiles CM, Hesp R et al. Cardiovascular effects of growth hormone treatment in growth-hormone deficient adults: stimulation of reninaldosterone system. Clinical Science 199181 587-592.

21 Shahi M, Beshyah SA, Hackett D, Sharp PS, Johnston DG \& Foale RA. Myocardial dysfunction in treated adult hypopituitarism: a possible explanation for increased cardiovascular mortality. British Heart Journal 199267 92-96.

22 Caidahl K, Edén S \& Bengtsson B-Å. Cardiovascular and renal effects of growth hormone. Clinical Endocrinology 199440 393-400.

23 Valcavi R, Gaddi O, Zini M, Iavicoli M, Mellino U \& Portioli I. Cardiac performance and mass in adult with hypopituitarism: effects of one year of growth hormone treatment. Journal of Clinical Endocrinology and Metabolism 199580 659-666.
24 Jörgensen JOL, Pedersen SA, Thuesen L et al. Beneficial effects of growth hormone treatment in GH-deficient adults. Lancet 1989 1 1221-1225.

25 Cittadini A, Cuocolo A, Merola B et al. Impaired cardiac performance in $\mathrm{GH}$-deficient adults and its improvement after $\mathrm{GH}$ replacement. American Journal of Physiology 1994267 E219E225.

26 Cuocolo A, Nicolai E, Colao A, Longobardi S, Cardei S, Fazio S et al. Improved left ventricular function after growth hormone replacement in patients with hypopituitarism: assessment with radionuclide angiography. European Journal of Nuclear Medicine 199623 390-394.

27 Amato G, Carella C, Fazio S, La Montagna G, Cittadini A, Sabatini $\mathrm{D}$ et al. Body composition, bone metabolism, heart structure and function in growth hormone deficient adult before and after growth hormone replacement therapy at low doses. Journal of Clinical Endocrinology and Metabolism 199377 1671-1676.

28 Fazio S, Cittadini A, Sabatini D, Merola B, Colao A, Biondi B et al. Growth hormone and the heart performance: a novel mechanism of cardiac wall stress regulation in humans. European Heart Journal 199718 340-347.

29 Fazio S, Cittadini A, Sabatini D, Merola B, Colao AM, Biondi B et al. Evidence for biventricular involvement in acromegaly: a Doppler echocardiographic study. European Heart Journal 1993 14 26-33.

30 Fazio S, Colao A, Sabatini D, Merola B, Riccio G, Ferone D et al. Effects of short-term acromegaly on cardiac morphology and function. In Abstracts of the ICE'96, San Francisco, June 12-15 1999. 1472 .

31 Pereira JL, Rodriguez-Puras MJ, Leal-Cerro A, Martinez A, GarciaLuna PP, Gavilan I et al. Acromegalic cardiopathy improves after treatment with increasing doses of octreotide. Journal of Endocrinological Investigation 1991 14 17-23.

32 Merola B, Cittadini A, Colao A, Ferone D, Fazio S, Sabatini D et al. Chronic treatment with octreotide improves cardiac abnormalities in patients with acromegaly. Journal of Clinical Endocrinology and Metabolism 199377 790-793.

33 Lim MJ, Barkan AL \& Buda AJ. Rapid reduction of left ventricular hypertrophy in acromegaly after suppression of growth hormone hypersecretion. Annals of Internal Medicine 1992117 719-726.

34 Witt SA, Glascock BJ, Kearfott-Hill KS, Bucuvalas JC, Daniels SR, Kour PR et al. A preliminary study of the effects of growth hormone on cardiac structure in adolescents during its use for the treatment of anorexia nervosa. Circulation 199796 I-89.

35 Cuneo RC, Wilmshurst P, Lowy C, McGauley G \& Sönksen PH. Cardiac failure responding to growth hormone. Lancet 1989 i 838-839.

36 Frustaci A, Perrone GA, Gentiloni N \& Russo MA. Reversible dilated cardiomyopathy due to growth hormone deficiency. American Journal of Clinical Pathology 1992 97 503-511.

37 Fazio S, Biondi B, Sabatini D, Cuocolo A, Tommaselli AP, Lombardi G et al. Long-term growth hormone deficiency as a cause of cardiomyopathy and its reversibility with specific replacement therapy. Journal of Clinical Endocrinology and Metabolism $199681887-890$.

38 Fazio S, Sabatini D, Capaldo B, Vigorito C, Giordano A, Guida R et al. A preliminary study of growth hormone in the treatment of heart failure in patients with dilated cardiomyopathy. New England Journal of Medicine 1996334 809-814.

39 Osterziel KJ, Strohm O, Schuler J, Friedrich M, Häulein D, Willenbrock R et al. Randomised, double-blind, placebo-controlled trial of human recombinant growth hormone in patients with chronic heart failure due to dilated cardiomyopathy. Lancet 1998 351 1233-1237.

40 Genth-Zotz S, Zotz R, Geil S, Voigtländer T, Meyer J \& Darins H. Recombinant growth hormone therapy in patients with ischemic cardiomyopathy. Effects on hemodynamics, left ventricular function, and cardiopulmonary exercise capacity. Circulation 199999 18-21.

41 Buerke M, Murohara T, Skurk C, Nuss C, Tomaselli K \& Lefer AM. Cardioprotective effect of insulin-like growth factor 
I in myocardial ischemia followed by reperfusion. Proceedings of the National Academy of Sciences of the USA 1995928031 8035 .

42 Li Q, Li B, Wang X, Leri A, Jana KP, Liu Y et al. Overexpression of insulin-like growth factor-I in mice protects from myocyte death after infarction, attenuating ventricular dilation, wal stress, and cardiac hypertrophy. Journal of Clinical Investigation $19971001991-1999$.

43 Wang L, Ma W, Markowich R, Chen J-W \& Wang PH. Regulation of cardiomyocyte apoptotic signaling by insulin-like growth factor I. Circulation Research 199883 516-522.

44 Frustaci A, Chimenti C, Setoguchi M, Guerra S, Corsello S, Crea F, et al. Cell death in acromegalic cardiomyopathy. Circulation 1999 99 1426-1434.

Received 16 July 1999

Accepted 11 November 1999 